\title{
Performance of Simulated Bioremediation in Real Samples of Soils Contaminated with PAHs
}

\author{
Roberta de Souza Pohren • Dilza Aparecida Nalin de Oliveira Leite • \\ Dejanira de Franceschi de Angelis • Vera Maria Ferrão Vargas
}

Received: 11 March 2016/Accepted: 13 June 2016 /Published online: 15 August 2016

(C) Springer International Publishing Switzerland 2016

\begin{abstract}
One of the possible ways of recovering the environmental quality of contaminated soils is the bioremediation process, in which soil pollutants are degraded using microorganisms. In this context, the evaluation of the bioremediation process efficiency was evaluated by preparing a consortium of autochthonous microorganisms of the soil from an area contaminated by wood preservatives. Subsequently, biodegradation experiments were performed on microcosm scale, applying bioaugmentation, enrichment and biostimulation techniques in two inoculums. The experiments were monitored by $\mathrm{CO}_{2}$ production and the presence of total polycyclic aromatic hydrocarbons (PAHs). Organic extracts of this soil were prepared before and after being
\end{abstract}

\footnotetext{
R. de Souza Pohren • V. M. F. Vargas $(\bowtie)$

Departamento de Pesquisas e Análises Laboratoriais, Fundação Estadual de Proteção Ambiental Henrique Luís Roessler (FEPAM), Avenida Salvador França, 1707, CEP: 90690-000 Porto Alegre, RS, Brazil

e-mail: vera.vargas@pq.cnpq.br

R. de Souza Pohren

e-mail: ropohren@gmail.com

R. de Souza Pohren · V. M. F. Vargas

Programa de Pós-graduação em Ecologia, Universidade Federal do Rio Grande do Sul (UFRGS), Av. Bento Gonçalves, 9500, CEP 91501-970 Porto Alegre, RS, Brazil
}

D. A. N. de Oliveira Leite - D. de Franceschi de Angelis Departamento de Bioquímica e Microbiologia, Universidade Estadual Paulista Júlio de Mesquita Filho (UNESP), Av. 24-A, 1515, CEP 13506-900 Rio Claro, SP, Brazil submitted to bioremediation, in which the 16 PAHs considered priority pollutants by USEPA were analyzed, and compared to the responses found for microbial respiration. The initial concentration of the PAHs was $34 \mathrm{mg} / \mathrm{Kg}$. All the treatments achieved a removal rate above $60 \%$, and the mean degradation was $88 \%$. Statistical analyses of the results of $\mathrm{CO}_{2}$ production showed a significant difference between all treatments for the control soil, except inoculum 1 (bioaugmented). However, inoculums 1 and 2 present a more efficient performance than the contaminated soil itself. When inoculums 1 and 2 (bioaugmented, biostimulated, and enriched) were compared, inoculum 2 presented a greater evolution of $\mathrm{CO}_{2}$ and a better performance in PAHs degradation. Therefore, it was more efficient in the experiment. Hence, as the best results were obtained with the inoculum whose mixed culture had been enriched, this technique definitely has a greater potential for biodegradation in bioremediation processes with these contaminants.

Keywords Biodegradation - Inoculum · Autochthonous microorganisms $\cdot$ Enrichment $\cdot$ Respirometry

\section{Introduction}

Soil contamination is one of the main environmental problems resulting from the mismanagement of existing natural resources. Among the main classes of contaminants that are of environmental concern are the polycyclic aromatic hydrocarbons-PAHs. These compounds 
are present in thousands of contaminated areas worldwide, 16 of them classified as priority pollutants by USEPA. These substances are considered toxic and persistent (Sayara et al. 2011; Mizwar and Triha 2015; Posada-Baquero and Ortega-Calvo 2011), and their degradation process in the soil is complex and not fully understood (Serrano et al. 2009). One of the alternatives for the remediation of contaminated areas by PAHs is bioremediation. This technique is considered promising and appears more sustainable than other decontamination technologies (Sayara et al. 2011; Moscoso et al. 2012; Sun et al. 2010; Trindade et al. 2005). However, so far it has been applied in less than $10 \%$ of the recovery of soil quality (Gillespie and Philp 2013), and it is necessary to perform laboratory-scale biodegradation experiments to strengthen the credibility of this technique (Haritash and Kaushik 2009; PosadaBaquero and Ortega-Calvo 2011).

Bioremediation can be developed by applying biostimulation and bioaugmentation processes. In bioaugmentation, there are added selected microorganisms that can tolerate and metabolize the contaminants of interest ( $\mathrm{Li}$ et al. 2009; Gillespie and Philp 2013), while biostimulation occurs by the addition of nutrients or electron receptors aiming to increase the autochthonous activity of soil. It also highlights that the two techniques may be applied jointly. The use of autochthonous microbiota as an inoculum is relevant, since the microorganisms present will be pre-adapted and supposedly capable of metabolizing the existing contaminants. In this context, there are known advantages to using consortia of bacteria and fungi. Through biodegradation synergy, they allow fungi to break down aromatic rings, followed by the action of bacteria on the metabolites generated (Sayara et al. 2011; Li et al. 2009). It must be considered that, when employed alone, most microorganisms do not have all the enzymes necessary to metabolize a xenobiotic completely. Thus, in order to present the action mechanisms that would be present in the natural environment, the metabolic pathways of microorganisms complement each other by microbial consortia (Jacques et al. 2007; Gaylarde et al. 2005).

One of the strategies to evaluate the metabolic activity of microorganisms in soil in a bioremediation process is to quantify the $\mathrm{CO}_{2}$ production resulting from microbial respiration in soil. This parameter indicates the biodegradation, allowing the total quantity of contaminants, such as PAHs mineralized by the action of microorganisms to be estimated (Bartha and Pramer 1965; Mariano et al. 2009; Serrano et al. 2009).

Most of the studies on PAH biodegradation work with the possibility of using autochthonous microorganisms from the sites with related contaminants. However, most use isolated microorganisms (Sun et al. 2010) or even consortia to degrade not the group of PAHs - as they would really present in contaminated environments - but only a specific $\mathrm{PAH}$ or against two, three compounds representing this chemical class (Li et al. 2008; Cerniglia 1992), in artificially contaminated soils. In this situation, there are gaps in the investigation of bioremediation considering the behavior of these complex mixtures in soils that are truly representative of the environment after long periods of contamination ( $\mathrm{Li}$ et al. 2009). Furthermore, these practices do not reflect the degradation process that occurs in natural environments in the presence of bacterial communities (Sun et al. 2010).

The objectives of this study were (i) to prepare a consortium of autochthonous microorganisms from PAH-contaminated soils; (ii) to examine the effect of bioaugmentation, enrichment, and biostimulation on biodegradation; and (iii) to evaluate the efficiency of the bioremediation of contaminated soil on a microcosm scale through $\mathrm{CO}_{2}$ production as an indicator of microbial metabolism and to quantify the concentrations of total PAHs present.

\section{Material and Methods}

\subsection{Contaminated Area and Soil Sampling}

The soil samples were collected in a contaminated area in the municipality of Triunfo in the State of Rio Grande do Sul, Brazil. There had been a wood preservatives industry at that site for over 40 years which was no longer active. Previously performed studies indicated the presence of the contaminants pentachlorophenol, creosote, metals (As, $\mathrm{Cu}$, and $\mathrm{Cr}$ ), and PAHs (Pohren et al. 2012; FEPAM/CNPq 2010). In this study, PAHs contamination from aged creosote-contaminated soil was given priority.

A composite sampling (pool) was performed from three areas (Fig. 1) with the highest values of pollutants of interest: PAHs, based on previous studies (Pohren et al. 2012). The sampling points to make up the pool of soil samples collected in the area were georeferenced (S 


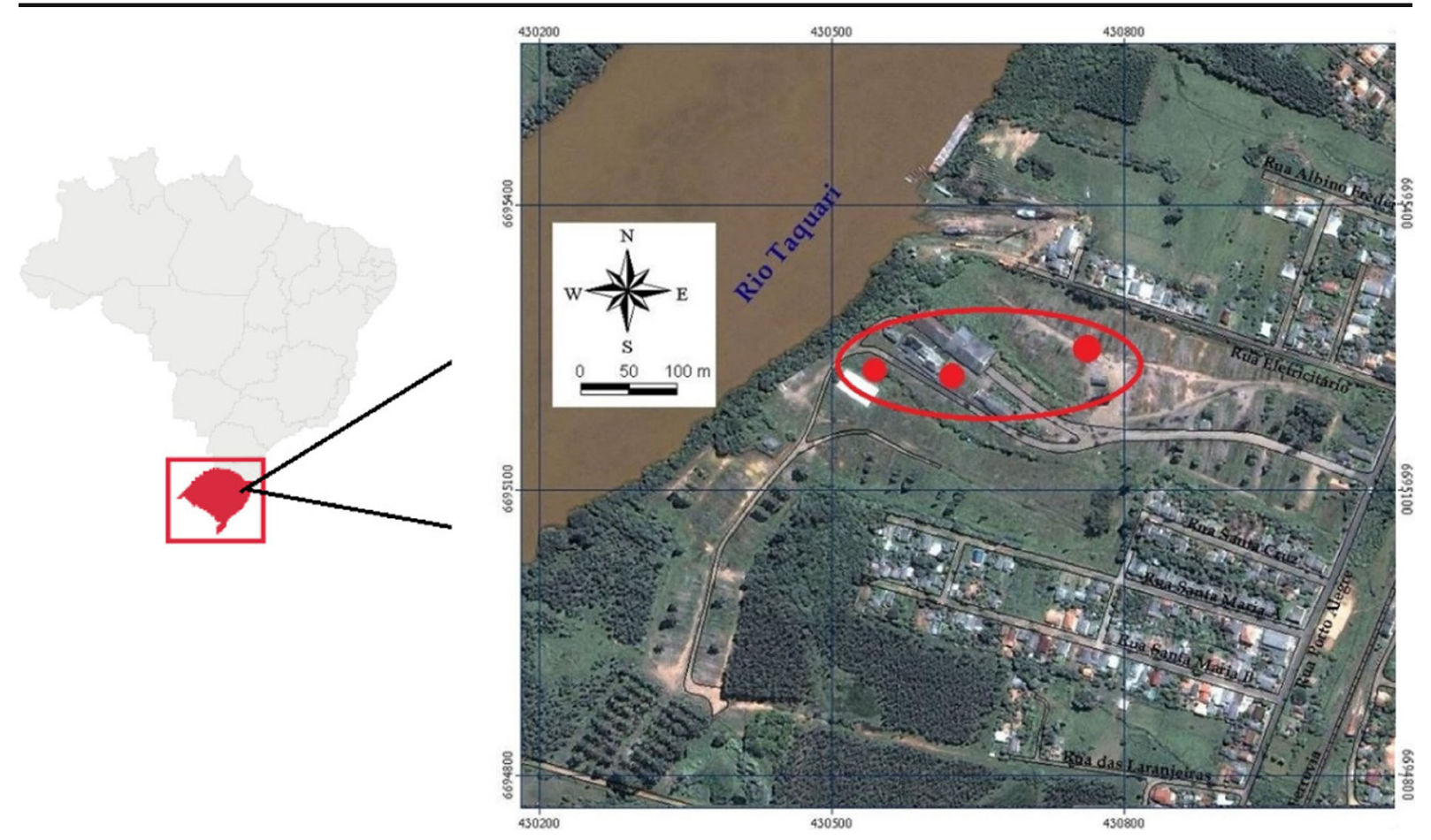

Fig 1 Soil contaminated site indicating the pool of sampled soils

$29^{\circ} 52^{\prime} 17.13^{\prime \prime}, \mathrm{W} 51^{\circ} 43^{\prime} 7.26^{\prime \prime}$; S $29^{\circ} 52^{\prime} 17.27^{\prime \prime}, \mathrm{W}$ $51^{\circ} 43^{\prime} 8.8^{\prime \prime}$; S $29^{\circ} 52^{\prime} 17.94^{\prime \prime}$, W $51^{\circ} 42^{\prime} 56.32^{\prime \prime}$ ).

The minimum period of 7 days without rain was observed to perform the sampling, and the recommendations of USEPA (1996) were followed. The samples were collected at points 0 to $20 \mathrm{~cm}$ deep, consisting of three subsamples, homogenized to obtain a single sample for each of the collection points, and after all the points placed together and homogenized composing a representative pool of the contaminated soil in the area (CS), which was stored in dark glass flasks and kept at $4{ }^{\circ} \mathrm{C}$ until it was used. The soil grain size analyses were performed using the simple classification method, the water content by gravimetry, and the field capacity according to EMBRAPA (1997). The pH was analyzed by DIGIMED/DM-22 potentiometry/pHmeter, organic carbon by the Walkley-Black method, total N Kjeldahl, analyzed as Standard Methods for the Examination of Water Wastewater (1995), and basic digestion and hexavalent chromium by a colorimetric method with diphenylcarbazide. Its main properties of the collected soil are as follows: texture: sand (48.3\%), silt (17.6\%), clay (12.8\%), and gravel (21.3); $\mathrm{pH} 6.3$; water holding capacity, $24 \%$; organic matter (o.m.), $3.4 \%$; organic carbon, $2.4 \%$; total N, $0.042 \%$; and $\mathrm{Cr}^{6+},<1 \mathrm{mg} / \mathrm{kg}$.

\subsection{Chemical Mediums and Reagents}

The PAHs phenanthrene, fluoranthene, pyrene, 1nitropyrene, 2-nitrofluorene (all with purity $>98 \%$ ) (Sigma-Aldrich) were selected and used in the degradation experiments. The stock solutions of individual PAHs were prepared in chromatographic grade solvent (acetone-Merck do Brasil) and used to form the pool of PAHs employed in the experiments. After the pool was applied to the soil, the solvent was evaporated under an $\mathrm{N}_{2}$, resulting in a final concentration of $4 \mathrm{~m} / \mathrm{kg}$ of each PAH in the soil. The PAH pool added corresponds to some representatives of the class of contaminants present in the soil in the area of this study, including high and low molecular weight, aiming to promote cometabolism and some PAH derivatives.

The following culture mediums were used: nutrient agar (NA) $1.8 \%$, plate count agar (PCA) $39 \mathrm{~g} / \mathrm{L}$, agar Sabouraud dextrose (SDA) $65 \mathrm{~g} / \mathrm{L}$, and BH mediumBuschell Hass (Difco ${ }^{\circledR}$ ), Blood agar, MacConkey and Cromoagar UriSELECT 4 (Bio-Rad Laboratories, Marnes-La-Coquete, France), containing (g/L) MgSO4, 0.2; $\mathrm{CaCl} 2,0.02 ; \mathrm{KH} 2 \mathrm{PO} 4,1.0 ; \mathrm{K} 2 \mathrm{HPO} 4,1.0$; $\mathrm{NH} 4 \mathrm{NO} 3,1.0 ; \mathrm{FeCl} 3,0.05 ; \mathrm{NaCl} 0.85 \%$; $\mathrm{KOH}$, $0.2 \mathrm{M}$; $\mathrm{HCl}, 0.1 \mathrm{M}$; and $\mathrm{BaCl} 2,0.5 \mathrm{M}$. After 
preparation, the culture mediums and dilution solutions were autoclaved at $120^{\circ} \mathrm{C}$ for $20 \mathrm{~min}$.

\subsection{Presence of Microorganisms}

The bacteria were cultured in general counting mediums and selective mediums. In order to perform a general count, the 10-g samples of contaminated soil (CS) were placed in erlenmeyers containing $90 \mathrm{~mL}$ of sterilized saline solution $\mathrm{NaCl} 0.85 \%$. The flasks were agitated in a shaker at $140 \mathrm{rpm}$ for $10 \mathrm{~min}$, at a temperature of $28 \pm$ $2{ }^{\circ} \mathrm{C}$. Then, aliquots were diluted into decimal series and submitted to plating. The rest was kept under refrigeration for later use in preparing the inoculums for evaluation.

The PCA culture medium containing cyclohexamine $15 \mu \mathrm{g} / \mathrm{mL}$ was used to count the bacteria, and for counting the filamentary fungi, the SDA medium with chloramphenicol $10 \mu \mathrm{g} / \mathrm{mL}$ was used, with a surface technique. The plates in triplicate were then incubated for $48 \mathrm{~h}$ at $35^{\circ} \mathrm{C}$ and 5 days at $28^{\circ} \mathrm{C}$, respectively for bacteria and fungi. After incubation, the colonies were counted and referenced as colony forming units per gram of dry soil $(\mathrm{CFU} / \mathrm{g} / \mathrm{ds})$. The morphologically identical colonies were isolated and submitted to identification. After isolation, the plates with PCA and SDA were reserved to compose the inoculums of the biodegradation tests.

A sample of $1 \mathrm{~g}$ of CS was added to $10 \mathrm{~mL}$ of sterile saline solution at $0.85 \%$, to perform a count in selective mediums and, after shaking, aliquots diluted in a decimal series were inoculated into the selective mediums to count the CFU per milliliter per gram. After $24 \mathrm{~h}$, and whenever necessary, up to 7 days of incubation, the plates were analyzed for the number of CFUs. The different morphological biotypes of the colonies were identified by standardized biochemical tests in a laboratory of Dr. Carlos E Levy at UNICAMP/SP.

Bacteria and fungi counts were compared among treatments using analysis of variance (ANOVA) with Bonferroni correction for multiple tests. For these analyses, data were transformed using log transformation. The statistical programs used were the "Statistical Analysis System" (SAS), version 9.2, and Statistical Package For The Social Sciences (SPSS/PASWSTAT), version 18.

\subsection{Preparation of Inoculums for Biodegradation Assays}

For the biodegradation assays, inoculums 1 and 2 were prepared from soil suspensions made for the general count of microorganisms. Among the plates containing decimal dilutions, colonies were selected with different biotypes predominant in the mediums. These colonies were later used to compose "inoculums 1 and 2" by transfer to a sterilized saline solution. Plates with the CS suspension were also prepared without dilution, and the microorganisms grown to compose the inoculum were leached.

Leaching was done by scraping the bacteria and fungi with a glass blade, using $\mathrm{NaCl} 0.85 \%$. Of the resulting liquid fraction, rich in soil microorganisms, $300 \mu \mathrm{L}$ were inoculated into an erlenmeyer containing $\mathrm{BH}$ medium. The microorganisms, which composed a mixed culture of fungi and bacteria, received the joint addition of counting suspensions of the microorganisms and also of the representative colonies. This resulted in a pool of autochthonous microorganisms composing the so called "inoculum 1." This consortium was incubated at $28 \pm 2{ }^{\circ} \mathrm{C}$ in a shaker at $200 \mathrm{rpm}$ for 7 days.

The "inoculum 2" was formed adding $10 \mathrm{~mL}$ of inoculum $190 \mathrm{~mL}$ of the $\mathrm{BH}$ medium, adding $2 \mathrm{~mL}$ of the $\mathrm{PAH}$ pool. The $\mathrm{BH}$ medium also received $0.05 \mathrm{~g}$ of glucose and $0.05 \mathrm{~g}$ of yeast extract. Inoculum 2 was kept in a shaker under agitation for 7 days at $28 \pm 2{ }^{\circ} \mathrm{C}$, for the microorganisms to adapt to the PAHs.

\subsection{Bioremediation Experiments}

\subsubsection{Microbial Metabolic Activity}

The laboratory-scale bioremediation experiments were performed using Bartha and Pramer respirometers, according to the biodegradation methodology described in Standard NBR ABNT 142831 and Technical Standard CETESB L6.350 (Bartha and Pramer 1965; NBR 14283 1999; CETESB 1990). The tests were performed at UNESP - Rio Claro/SP. Fifty grams of CS were added to the respirometry flask with moisture level adjusted to $60 \%$ of soil water holding capacity. Each flask of microcosm received $0.2 \mathrm{~mL}$ of inoculum containing $1 \times 10^{7} \mathrm{CFU} / \mathrm{mL}$ in the corresponding treatments. Table 1 shows the experimental protocol performed in triplicates.

High values of $\mathrm{C} / \mathrm{N}$ lead to slow degradation processes. This required the addition of materials to aid in soil biodegradation process, such as fertilizers and organic compounds. Thus, the addition of materials such as fertilizers and organic compounds was necessary to improve the soil biodegradation process. An already stabilized solid compound from composting $(0.5 \%)$ 
Table 1 Experimental protocol of biodegradation in the respirometers

\begin{tabular}{ll}
\hline Treatments & Respirometric experiments \\
\hline $1 \mathrm{CS}$ & Contaminated soil - control \\
$2 \mathrm{CS}$ & Soil + inoculum 1 \\
$3 \mathrm{CS}$ & Soil + PAH pool \\
$4 \mathrm{CS}$ & Soil + inoculum 1+ PAH pool \\
$5 \mathrm{CS}$ & Soil + solid compound \\
$6 \mathrm{CS}$ & Soil + liquid fertilizer \\
$7 \mathrm{CS}$ & Soil + inoculum 1+ solid compound \\
$8 \mathrm{CS}$ & Soil + Inoculum 1+ liquid fertilizer \\
$9 \mathrm{CS}$ & Soil + inoculum 2 \\
$10 \mathrm{CS}$ & Soil + inoculum 2 + PAH pool \\
\hline
\end{tabular}

CS contaminated soil

was added to treatments $5 \mathrm{CS}$ and $7 \mathrm{CS}$, and liquid fertilizer from the agricultural degradation of vine residue $(0.5 \%)$ was added to $6 \mathrm{CS}$ and $8 \mathrm{CS}$. The microcosm soil was adjusted to maintain the $60 \% \mathrm{FC}$ of the soil.

The respirometers were incubated at $28 \pm 2{ }^{\circ} \mathrm{C}$ (dark) for 60 days and examined periodically for the $\mathrm{CO}_{2}$ content as an indicator of the microbial respiration involved in the degradation of organic compounds in soil. The $\mathrm{CO}_{2}$ produced during the experiment is neutralized in a solution of $\mathrm{KOH}(0.2 \mathrm{M})$ located in the respirometer. The amount of gas released is quantified by the titer of the residual $\mathrm{KOH}$ with $\mathrm{HCl}$ and addition of $\mathrm{BaCl}_{2}$. During this procedure, the respirometers were aerated through filters with soda lime with replacement of a new solution of $\mathrm{KOH}$. Every day of the evaluation of $\mathrm{CO}_{2}$ evolution during biodegradation, a blank test was performed in a Becker containing $10 \mathrm{~mL}$ of a solution of $\mathrm{KOH}$, phenolphthalein, and $\mathrm{BaCl}_{2}$.

In order to perform the calculations, the production of $\mathrm{CO}_{2}$ of the respirometer used as control was subtracted from the mean production of the others in the experiment. The $\mathrm{CO}_{2}$ was quantified by the daily production and referenced by the accumulated evolution for each of the treatments. The equation used was $\mu \mathrm{mol} \mathrm{CO}_{2}$ soil $=$ $(A-B) \times 50 \times f_{\text {HCI, }}$ where $A=$ volume of $\mathrm{HCl} 0.1 \mathrm{M}$ to titrate $\mathrm{KOH}$ of the $\mathrm{CS} / \mathrm{Control}$, in $\mathrm{mL} ; B=$ volume of $\mathrm{HCl} 0.1 \mathrm{M}$ to titrate $\mathrm{KOH}$ of the respirometer with the soil of treatments in $\mathrm{mL} ; 50=$ factor to transform equivalent into $\mu \mathrm{mol}$ of $\mathrm{CO}_{2}$; and $f_{\mathrm{HCl}}=$ correction factor of the $\mathrm{HCl} 0.1 \mathrm{M}$ solution.

After the incubation period of the respirometers, the $\mathrm{CS}$ of the triplicates was joined together and submitted to microbial counting and to organic extraction to recover the residual PAHs in order to look at bioremediation efficiency.

The data on accumulated production of $\mathrm{CO}_{2}$ produced during 60 days in the different treatments were submitted to analysis of variance (ANOVA) for repeat measures and Bonferroni's test for multiple comparisons. Pearson's correlations were performed to look at the relation between $\mathrm{CO}_{2}$ production and the concentration of the different PAHs. The statistical programs used were the Statistical Analysis System (SAS), version 9.2, and Statistical Package For The Social Sciences (SPSS/PASWSTAT), version 18.

\subsubsection{Evaluation of the Total PAHs Present in the Soil}

The organic extracts of soils before and after performing the respirometric assay for biodegradation were obtained according to the USEPA - U.S. Environmental Protection Agency (2007; 1996a, b) method; $15 \mathrm{~g}$ of soil were homogenized and dichloromethane (DCM) solvent was added, submitted to extraction using ultrasound. These extracts were filtered in a chromatographic column of sodium sulfate and celite. They were then concentrated in a rotavapor and stored under refrigeration. The PAHs were quantified by gas chromatography coupled to the mass spectrometer (GC/MS Perkin Elmer model Clarus 600 quadrupole system in SIR mode) focusing on 16 species classified as priority pollutants by USEPA: acenaphthene, acenapthylene, anthracene, benzo(a)anthracene, benzo(a)pyrene, benzo(b)fluoranthrene, benzo(b)perylene, indeno(1,2,3-cd)pyrene, benzo(k)fluoranthrene, crysene, dibenzo(a,h)anthracene, phenathrene, fluoranthrene, fluorene, naphthalene, and pyrene, according to the USEPA SW846/8270-D method. The results were expressed as total PAHs present.

The percentage reduction was calculated as $\%$ BiodPAHs $=[(\mathrm{CHi}-\mathrm{CHf}) / \mathrm{CHi}] \times 100$, where $\mathrm{CHi}$ is the initial concentration of the PAHs and CHf is the final concentration of the PAHs (Sayara et al.; Sun et al. 2010).

\section{Results and Discussion}

3.1 Bacteria and Fungi Present in the Contaminated Soil

The number of bacteria and fungi present in CS before the experiments was $5.35 \times 10^{7} \mathrm{CFU} / \mathrm{g} / \mathrm{ds}$ and $1.25 \times 10^{4} \mathrm{CFU} / \mathrm{g} / \mathrm{ds}$, respectively. When the same soil 
in the region, used as reference, was evaluated, the following was found, respectively, for bacteria and fungi: $1.2 \times 10^{6}$ and $1.4 \times 10^{2} \mathrm{CFU} / \mathrm{g} / \mathrm{ds}$. This difference in the number of microorganisms may indicate that some organic substrate is being used.

A diminished number of $\mathrm{CFU} / \mathrm{g} / \mathrm{ds}$ of bacteria were recorded in all treatments, when the counts in CS are compared before and after the end of the biodegradation experiments (Fig. 2). Thus, it is noted that even in the treatments where nutritional stimuli were added, not all microorganisms benefitted and increased their populations. This means that some of the bacteria and fungi present were unable to access the necessary nutrients and/or minerals, or diminished their number by competition or other limiting factors. Although this reduction occurred, in terms of contaminant degradation, the results show that no inhibitory effects on the bacterial population were presented, that could degrade the contaminants of interest. Even with these variations regarding the initial population, numerically, the autochthonous microorganisms were enough to promote biodegradation. In studies performed with respirometers of Bartha and Pramer (Mariano et al. 2009), often, the number of microorganisms obeys the Gauss curve. Outstanding among the possible reasons are competition, depletion of nutrients, production of antagonic metabolites, and the condition of the respirometers themselves.

In the control soil (1CS), as well as in the other treatments, the number of bacteria diminished after 60 days. The development of the autochthonous population was restricted indicating the need to provide nutrients and/or enrichment to keep the population viable.
As to the CS, there was a similar count of bacteria and fungi (Fig. 2) in treatments with bioaugmentation and/or biostimulation (2CS and 9CS), possibly indicating the need for some additional source of carbon to promote population development, since the soil is poor in organic matters (o.m.). In bacteria counts, a significant difference was observed between the treatment 1CS and all others, except 7CS, with $p$ value $<0.001$. As for the treatments with inoculums, $2 \mathrm{CS}$ and $9 \mathrm{CS}$, they differed only from $1 \mathrm{CS}$ and 3CS with $p<0.001$.

According to the values of the fungi found in CS 1,2, and 9 , the increase of inoculums did not have much influence, no significant difference between treatments. In the other treatments with biostimulation and enrichment, the values were higher and may be associated with the growth of the present population itself because of the addition of nutrients, although not statistically significant.

These results further clarify the responses obtained, since a statistical analysis of data on $\mathrm{CO}_{2}$ production showed a significant difference between all treatments in relation to the control soil. However, when inoculum 1 (bioaugmented) and inoculum 2 (bioaugmented, biostimulated, and enriched) are compared, it is found that inoculum 2 presented a greater evolution of $\mathrm{CO}_{2}$ and better performance in the degradation of the contaminants of interest.

In the case of the soil that received the contribution from the PAH pool (3CS), more bacteria and fungi developed compared to the other treatments, with $p$ values ranging from 0.001 to 0.05 . This result indicates that even with the concentration of the PAH pool added to the CS, there was no inhibition of growth of the native microbiota, rather, it was stimulated. This proportion
Fig 2 Mean quantification of bacterial and fungal $\mathrm{CFU} / \mathrm{g} / \mathrm{ds}$ after respirometric treatments

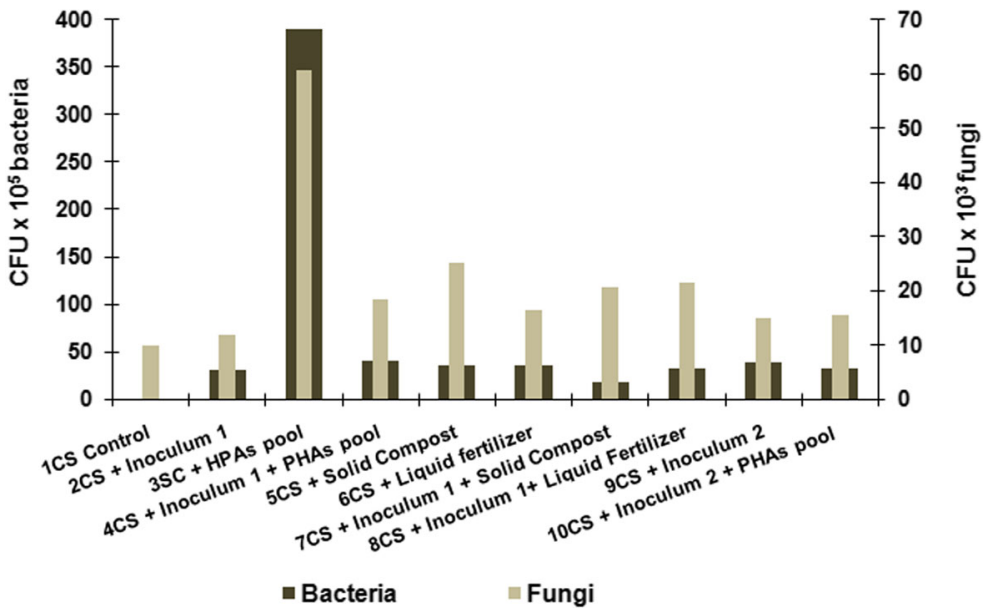


which is outstandingly superior in $3 \mathrm{CS}$ indicates that other treatments may have favored some species of bacteria/fungi, or have presented more limited conditions for the development of the same number found in the control soil. The greater number of microorganisms may be considered the result of the autochthonous population well adapted to the type of contaminant used for enrichment. Hence, it can be said that the bacteria and fungi found in the soil of the contaminated area managed to adapt to the new concentration of PAHs. This response pattern indicates that the soil has, naturally, a resistant population adapted to the contaminants of interest in the study and detected during the time of the experiment.

After seeding microorganisms in the selective mediums, the bacteria were identified from the plates inoculated with diluted aliquots of $1 \times 10^{3}$ for bacteria and $1 \times 10^{2}$ for fungi. The colonies isolated in the selective mediums were identified and inserted in Table 2.

The bacterial and fungal strains with the capacity to degrade PAHs often reported in the literature are Pseudomonas sp., Bacillus, Burkholderia, Sphingomonas, Actinetobacter sp., Flavobacterium sp., among others (Jacques et al. 2005; Haritash and Kaushik 2009; Cerniglia 1992), as well as some fungi, such as Aspergillus, Cladosporium, Fusarium, Trichoderma, Phanerochaete, Lentinus, etc. (Serrano et al. 2009; Haritash and Kaushik 2009; Giraud et al. 2001).

In biodegradation studies, the inoculation of mixed cultures is outstandingly relevant - associating species of fungi and bacteria. These mixed cultures will use different strategies that are, however, complementary

Table 2 Mean quantification of the CFU/g/ds of bacteria identified in the contaminated soil

\begin{tabular}{ll}
\hline Microorganisms & Final count \\
\hline Bacillus sp. & $8.0 \times 10^{6}$ \\
Acinetobacter baumannii & $5.8 \times 10^{7}$ \\
Pseudomonas sp. & $3.0 \times 10^{7}$ \\
Pseudomonas putida 1 & $1.6 \times 10^{7}$ \\
Pseudomonas putida 2 & $1.1 \times 10^{7}$ \\
Pseudomonas aeruginosa & $2.3 \times 10^{7}$ \\
Enterobacter cloacae & $>10^{7}$ \\
Pantoea sp. & $>10^{7}$ \\
Burkholderia cepacia & $2.0 \times 10^{6}$ \\
Enterobacter aerogenes & $3.8 \times 10^{4}$ \\
Serratia sp. & $1.8 \times 10^{4}$ \\
Klebsiella pneumoniae & $7.0 \times 10^{4}$ \\
\hline
\end{tabular}

in the degradation of substrates, including the PAHs. Among the bacteria identified Pseudomonas sp., P. putida and P. aeruginosa are known to present a high potential for degradation compared with crysene, fluoranthene, pyrene, and benzo(a) anthracene in supplemented mediums (Trzesicka-Mlynarz and Ward 1995). Another bacteria among those that were identified, Burkholderia cepacia can degrade fluoranthene and benzo(a)anthracene, and also fluorene in PAHs originating in creosote (Juhasz et al. 1997). For the oxidation of phenanthrene, according to Kim et al. (2009), Acinetobacter baumanni was able to degrade phenanthrene; concordant results were also found in a study by Aitken et al. (1998) for genera Burkholderia and Pseudomonas, among others shown by the study mentioned.

The dominant fungi colonies were isolated and identified as: Cladosporium sp., Penicillium sp., Trichoderma sp., Fusarium sp., and Aspergillus fumigatus. Among these, the action of genera Cladosporium, Aspergillus sp., and Fusarium is well known to biodegrade some types of PAHs, such as benzo(a)anthracene and benzo(a)pyrene (Giraud et al. 2001; Serrano et al. 2009; Haritash and Kaushik 2009; Lladó et al. 2013a). Besides these, some species of Trichoderma are known for the capacity to metabolize naphthalene, phenathrene, crysene, pyrene, and benzo(a)pyrene (Zafra and Cortés-Espinosa 2015).

Although the microbial identification is simple, it enables a view of the richness of this soil with such a diverse contamination and submitted to pollutants for decades in a real environment, which does not occur in most studies to evaluate the bioaugmentation and biostimulation techniques when experiments are performed with artificially contaminated and/or sterilized synthetic soil samples (Semple et al. 2007).

\subsection{Evaluation of the Efficiency of Inoculums 1 and 2}

The continuous quantification of $\mathrm{CO}_{2}$ during the experiment shows the metabolic activity of the microorganisms, so that it is possible to compare the performance of the consortia prepared. It was found that the production curve of $\mathrm{CO}_{2}$ did not present the "phase lag" (Fig. 3) that would indicate the period of adaptation of the microorganisms to the substrate added. Figure 2 indicates that the microorganisms were able to metabolize the PAH molecules present in the soils of the respirometers. According to the pattern of $\mathrm{CO}_{2}$, evolution curves, the microbial metabolism obeyed a constant evolution 
of $\mathrm{CO}_{2}$ and was completely consumed during the 66 days in which the experiment was followed.

The $\mathrm{CO}_{2}$ production responses were significantly different from the amount generated by the control soil (1CS), except the response for the 2CS treatment (soil bioaugmented with inoculum 1). It should, however, be mentioned that inoculum 2 (treatment 9CS) significantly improved biodegradation. As the days go by, however, the difference in the production of $\mathrm{CO}_{2}$ between treatments 2 and 9 (with the inoculums) grows, favored by the addition of microorganisms and by biostimulation. Inoculum 2 shows a greater generation of biodegraded carbon already from the beginning of the experiment, when the degradation of some more labile substances may have occurred; the evolution continued parallel and continuously in relation to inoculum 1 . The microorganisms of inoculum 2 were previously exposed to the PAHs. This enrichment may have induced a preadaptation or selection of microorganisms more tolerant to PAHs than those of inoculum 1. Until the 24th day, the $\mathrm{CO}_{2}$ production curves presented a similar behavior. However, treatment $1 \mathrm{CS}$ indicated a decrease in $\mathrm{CO}_{2}$ production. Considering the experimented projected over time, probably the curves of inoculums 1 and 2 would tend to stabilize, indicating behaviors similar to those of the prepared inoculum, toward the contaminated soil- differently from what would happen with the control treatment of the area itself (1CS) that tends to stabilize faster, as indicated in Fig. 3.

The control soil (1CS) can be considered as a site submitted to natural attenuation. However, evaluating $\mathrm{CO}_{2}$ production in the microcosm experiments, higher production was observed where microbial enrichment occurred in the samples to be biodegraded, and it can be inferred that the soil in the area benefits from the inoculums added. It should be highlighted that inoculums 1 and 2 (treatments 2 and 9, respectively) have a similar metabolic performance, more efficient than the contaminated soil itself (1CS). This demonstrates that the increased quantity of pre-adapted organisms in the substrate favors faster degradation of the contaminants, as recorded at $2 \mathrm{CS}, 7 \mathrm{CS}$, and $8 \mathrm{CS}$. In this experiment, it is emphasized that the solid compound and liquid fertilizer are stabilized products, and the response found in $6 \mathrm{CS}$ and $8 \mathrm{CS}$ - treatments that received these nutrientsreflects the degradation of the contaminants present in the soil of the contaminated area, whose difference to each other was not statistically significant. It is found, however, that the action of the nutrients offered by the fertilizer associated with the inoculum added favored the evolution of $\mathrm{CO}_{2}$ (Fig. 3). The soil to which only the liquid fertilizer was added responded with a lower production of $\mathrm{CO}_{2}$. It should be pointed out that this behavior of inoculum 1 in relation to the addition of liquid fertilizer is justified since this inoculum did not receive the input of yeast extract and glucose, and despite this, the microbial community remained viable. However, the possibility should be considered of increased biodegradation due to the input of humic material that can make the desorption of PAHs easier (Sayara et al. 2011; Semple et al. 2007).

The presence of the nutrients from liquid fertilizer added to the soil in the area (8CS) changes the response pattern of the action of inoculum 1, with a rapid evolution of $\mathrm{CO}_{2}$ from the sixth day onward. The presence of micronutrients of this product may have favored the growth of the microorganisms that are originally in the soil, making biodegradation easier in the first 6 days. Experiments with the addition of compounds and fertilizers may mean the presence of humic materials which induce increased stability, acting as surfactant and releasing PAHs sorbed into the soil (Megharaj et al. 2011; Sayara et al. 2011), the liquid fertilizer used in the experiment having a concentration of $6.4 \%$ of humic acids. In this study, mixed microbial cultures that are potential producers of biosurfactants were inoculatedeven though this was not analytically evidenced. This inoculation together with the addition of liquid fertilizer may induce the natural formation of molecules as biosurfactants. The presence of biosurfactants induces mobility and bioavailability of insoluble compounds, favoring pollutant biodegradation (Rahman et al. 2003).

Likewise, when a substrate is enriched with nutrients that can be metabolized by microorganisms, respiratory activity will be associated with this biostimulation. Therefore, the introduction of the PAH pool for the microbial consortium in the soil- even when it does not undergo adaptation resulting from manipulation in the laboratory - showed that it contributes to the greater evolution of $\mathrm{CO}_{2}$, as recorded by the response of treatment 3CS. This demonstrates that the autochthonous microorganisms present in the soil collected, despite not being bioaugmented, over time can degrade the contaminants under the conditions of the experiment and are helped by the natural adaptation of microorganisms to the PAH molecules. During the follow-up period of $\mathrm{CO}_{2}$, production, treatments with a PAH pool produced more $\mathrm{CO}_{2}$ than the control soil. No inhibition of 


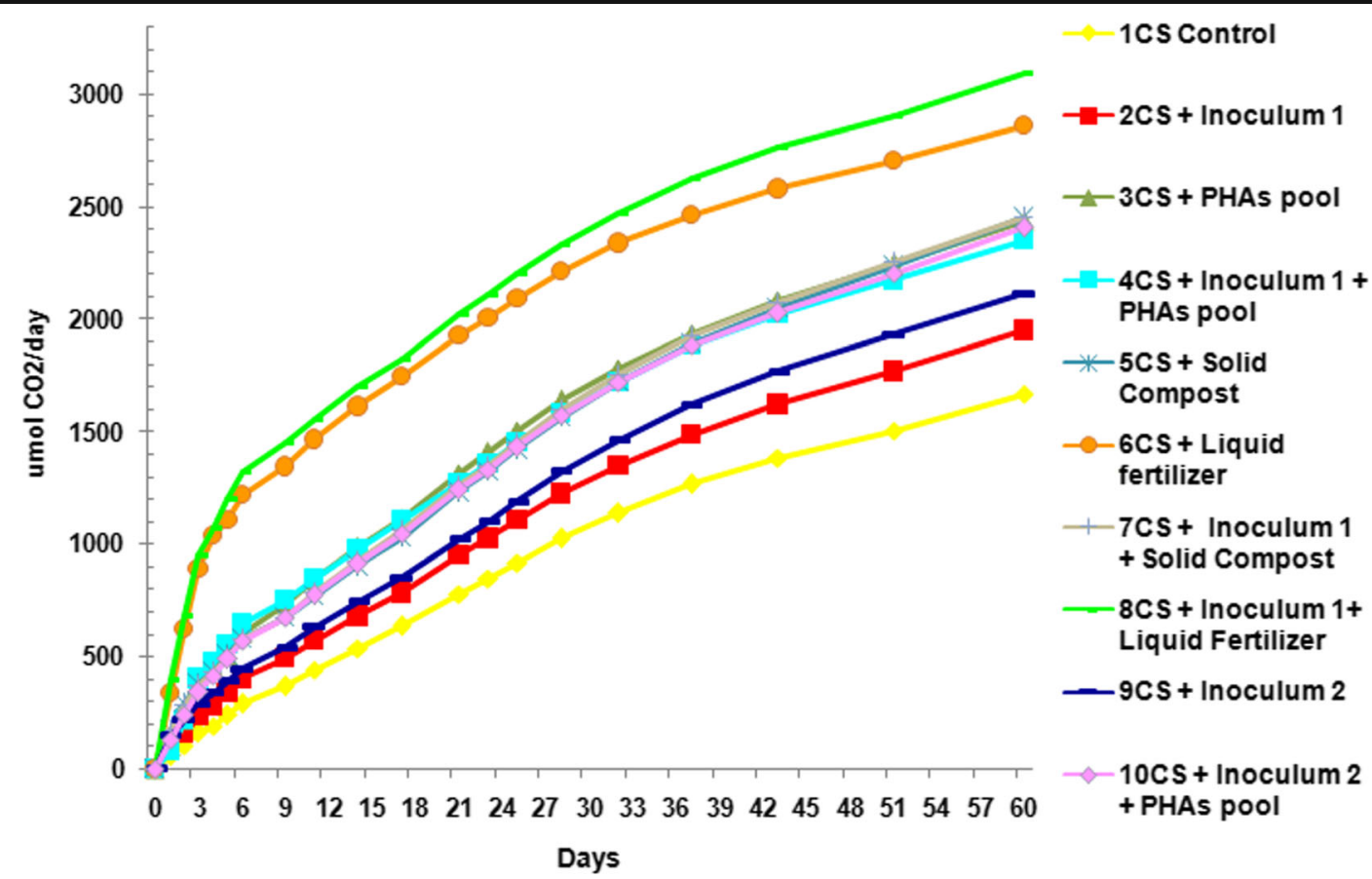

Fig 3 Accumulated production of $\mathrm{CO}_{2}$ /day in the biodegradability tests using Bartha's respirometry

metabolic activity was found, and from the continuous $\mathrm{CO}_{2}$ production, contaminant degradation can be considered to have occurred.

Inoculum 2 with the pool-enriched and adapted $10 \mathrm{CS}$ - pointed to a greater evolution of $\mathrm{CO}_{2}$ compared to the previously bioaugmented inoculum 1 (4CS). In treatments $3 \mathrm{CS}, 9 \mathrm{CS}$, and $10 \mathrm{CS}$, a greater $\mathrm{CO}_{2}$ production was detected compared to $1 \mathrm{CS}$, and also found for biodegradation in the same type of microcosm with soils artificially contaminated with PAHs (Serrano et al. 2009). Although the percentage reduction with the addition of the PAH pool increased compared to $1 \mathrm{CS}$, when compared to the soil with the addition of the PAH pool, the inoculums do not increase biodegradation of the treatments. However, under conditions in which the experiment lasts longer, the microorganisms could achieve greater adaptation and show differentiated effects.

As observed, the metabolic activity of the microorganisms may vary during biodegradation. According to the study that evaluated the degradation of TPHs in recently contaminated soil (Trindade et al. 2005) submitted to bioaugmentation and biostimulation, decreases are probably due to the beginning of the degradation of another profile of molecules, the more recalcitrant ones, as in the case of the high molecular weight
PAHs, with four or more aromatic rings. Slowdowns during the process may indicate the difficulty of microorganisms present in the microcosm to continue their metabolic routes of degradation of the available pollutants. Many factors could be associated with this pattern of microorganism behavior in degradation, and this may be related to limitations regarding the transfer of contaminants, with greater sorption of hydrophobic organic contaminants - such as PAHs - to the soil matrix, diminishing the percentage and extent of biodegradation, because they prevent the bioavailability of the existing contaminants (Kottler and Alexander 2001; White et al. 2007).

Soil properties, such as o.m. content and the predominant grain size fraction, play a decisive role in contaminant biodegradation. The PAHs are hydrophobic, and therefore, they tend to sorption in the solid phase of soil (Haritash and Kaushik 2009). Therefore, the fraction that is sorbed becomes inaccessible to microorganisms. The presence of sand (48.3\%) may have influenced the biodegradation of the main PAHs analyzed, although it was not expressed in the conversion to $\mathrm{CO}_{2}$ - since other degradation products may have been generated. The ability of soil to desorb the pollutants determines its susceptibility to microbial degradation and the effectiveness of bioremediation, and the pollutants and other 
substrates must be available (Megharaj et al. 2011). Since it is a sandy soil, the pollutants present are more accessible and available for biodegradation (Guerin 1999; Trindade et al. 2005). This situation can be confirmed by the approach involving the low o.m. concentrations present, which may have made it easier for the microorganisms to perform metabolization.

In this study, the best results were obtained using the bioaugmented and biostimulated inoculum. This shows a greater potential for biodegradation in bioremediation processes.

\subsubsection{Analysis of PAHs}

The initial total concentration of the 16 PAHs was $34 \mathrm{mg} / \mathrm{kg}$ (Fig. 4). All the treatments reached a percentage reduction of PAHs in soil above $60 \%$, and the mean degradation efficiency was $88 \%$. This performance provides an indicator of effective potential to be used in bioremediation. The highest percentage of degradation detected after performing the respirometric tests was observed in treatment $8 \mathrm{CS}$ (soil + inoculum $1+$ liquid fertilizer), presenting a lower residual value of $1.58 \mathrm{mg} / \mathrm{kg}$ of total PAHs, which is in accordance with the response of greater respiratory activity, as demonstrated by $\mathrm{CO}_{2}$ production in this treatment in the assay of biodegradation in microcosms.

The values obtained in the treatments that received the inoculums prepared presented the greatest reduction of target pollutants. This was proved when the percentages of degradation of the sum of total PAHs in soil were compared before bioremediation and after the treatments (Table 3).

The degradation of the more recalcitrant PAHs, particularly those with a higher molecular mass, is facilitated by the presence of the slow growing populations. These microorganisms are prevalent when nutrients are scarce (Johnsen and Karlson 2007). Although in 1CS compounds with high molecular weight predominate as remnants (Table 3 ), there is a considerable percentage of biodegradation. This response should be noted since the soil has not received any input. This shows that microorganisms of the contaminated area after a long time of adaptation to this contaminant profile manage to biodegrade contaminants or more recalcitrant metabolites. The responses obtained show the need for bioaugmentation, biostimulation, and also enrichment even in soils exposed for a long time to contaminants in order to maximize the efficiency of bioremediation processes. The lowest percentage biodegradation for recalcitrant PAHs (from five to six rings) occurs in the control soil, without nutritional addition or bioaugmentation. On the other hand, the treatments that were biostimulated with a pool of PAHs presented a high percentage of degradation. This indicates through another mechanism, that enrichment favors the activation of the autochthonous microorganisms. This biostimulation may have activated the microbiota that are resistant to metabolizing PAHs of different molecular masses, including those with a high MW. This was also found in the study of Li et al. (2009) with low concentrations of PAHs in soils of a longtime contaminated area, where one of the possibilities
Fig 4 Concentration of total PAHs before and after biodegradation experiments

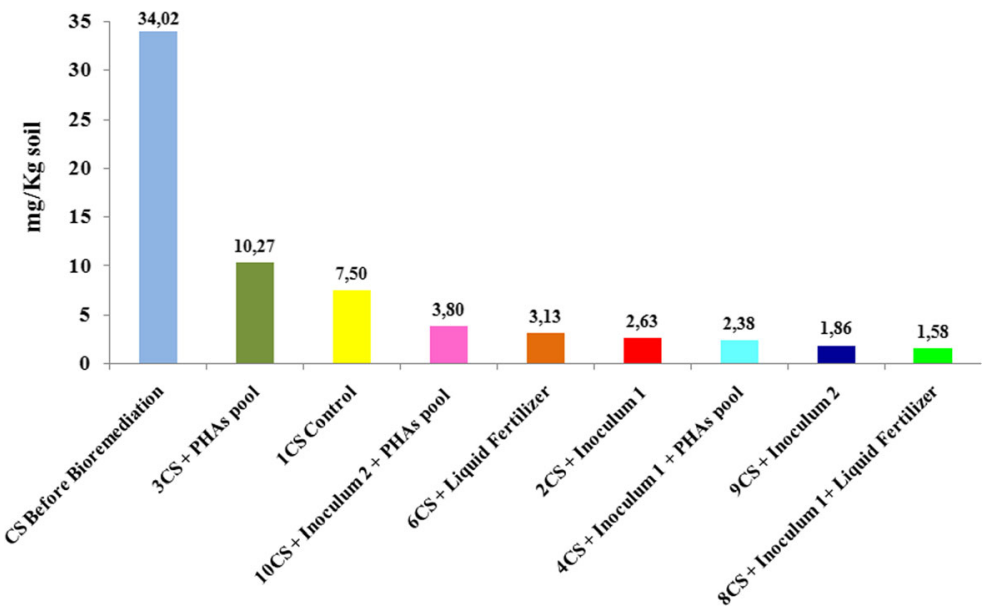


considered was the contact favored between fungus mycelia and contaminants due to the long time of contamination.

Consortium is bacterial-fungus are more likely to promote more effective biodegradation (Boonchan et al. 2000; Lladó et al. 2013b; Li et al. 2008). Fungi such as Coriolopsis, Bjerkandera, Penicillium, and others have proved efficient in relation to biodegradation of high molecular mass PAHs. Fungal exoenzymes are considered more efficient than bacteria in the initial attack of more complex PAHs. The fungal exoenzymes can go further in disseminating and reaching the compounds. In natural environments, these microorganisms coexist in soil and there is catalytic and synergistic cooperation between them. As in this work, in other studies (Boonchan et al. 2000; Li et al. 2009; Li et al. 2008) high rates of degradation of high molecular mass biodegradation were found after the inoculation of autochthonous microorganisms. These studies suggest that the inoculation the inoculation of mixed cultures from contaminated soil may have been responsible for the bioavailability and consequently the decrease of PAHs concentration. It is considered that the respirometer conditions can make contact easier between existing microorganisms, between the contaminants, humidity, and electron acceptors, leading to efficient bioremediation.

According to a correlation analysis, it was observed that only the following PAHs, crysene, naphthalene, acenaphtylene, anthracene, phenanthrene fluorine, and pyrene, appeared to be related to $\mathrm{CO}_{2}$ production, with

Table 3 Degradation of PAHs (BiodPAHs) in each of the treatments regarding the CS before bioremediation and percent of PAHs remaining after microcosms (CS)

\begin{tabular}{llll}
\hline & $\begin{array}{l}\text { BiodPHAs } \\
(\%)\end{array}$ & $\begin{array}{l}\text { \% high } \\
\text { MW }\end{array}$ & $\begin{array}{l}\text { \% low } \\
\text { MW }\end{array}$ \\
\hline $\begin{array}{l}\text { 8CS + inoculum 1 + liquid } \\
\text { fertilizer }\end{array}$ & 95.5 & 34.8 & 65.2 \\
9CS + inoculum 2 & 95.5 & 44.5 & 55.5 \\
$\begin{array}{l}\text { 4CS + inoculum 1 + PHAs } \\
\text { pool }\end{array}$ & 93.0 & 51.7 & 48.3 \\
$\begin{array}{l}\text { 2CS + inoculum 1 } \\
\text { 6CS + liquid fertilizer }\end{array}$ & 92.3 & 54.1 & 45.9 \\
$\begin{array}{l}\text { 10CS + inoculum 2 PAH pool } \\
\text { 1CS control }\end{array}$ & 88.8 & 53.3 & 48.7 \\
3CS + PAH pool & 78.0 & 66.5 & 57.1 \\
\hline
\end{tabular}

$M W$ molecular weight $r=0.76502,0.72567,0.75951,0.81288,0.81081$, 0.78288 , and 0.80677 values, respectively. Hence, it could be considered that the recalcitrant PAHs (five and six rings) are not associated with the generation of $\mathrm{CO}_{2}$ measured; the biodegradation of these compounds appears to generate intermediate by-products instead of reaching the integral mineralization route.

Considering the PAHs individually in relation to the initial concentration in CS (Table 4), it was found that the highest percentage of degradation occurred for naphthalene $(99.6 \%)$. Due to the physicochemical properties, because it is a light PAH, this compound has high rates of degradation under the action of adapted microbiota. It is underscored that in the cases of compounds such as naphthalene and other light compounds, given their physicochemical characteristics, their high rates of degradation are possibly influenced by loss due to the volatility inherent to these molecules. The high rates of degradation were also observed by Lladó et al. (2013a), in a study on soils that had suffered the impact of creosote for many years, where high molecular mass PAHs such as phenanthrene, for instance, presented a degradation of $95 \%$ under fungal action.

Other compounds with the highest rates of degradation were benzo(k)fluoranthene, with $99 \%$ (five rings), pyrene with $98.8 \%$ (four rings), crysene with $98.7 \%$ (four rings), and benzo(g,h,i)perylene with $97.5 \%$ (six rings). In another study, also with autochthonous microbial cultures in soil from an area contaminated by PAHs (Sun et al. 2010), high rates of degradation were also found for compounds such as pyrene and fluoranthene, 82.8 and $96.2 \%$, respectively. It should be highlighted that this performance shown for recalcitrant PAHs may be the result of cometabolism. In this process, the compound is not used directly as a nutrient or source of energy; the intermediary metabolites produced by some organisms will serve as substrates for the growth of others (Serrano et al., 2009; Li et al. 2008). Consequently, this may lead to partial degradation if there are no enzymes that can transform the metabolites generated. In this case, the co-metabolizing population degrades the substrate, but does not benefit for its growth, with no increase of the microbial population. This is evidenced by the diminished number of microorganisms estimated by counting.

The co-metabolic processes are more likely since there is an increase in the number of aromatic rings, i.e., in the degradation of high molecular weight PAHs. 
Table 4 Initial concentration of PAHs in contaminated soil before biodegradation in the respirometry assays and final percentage reduction of individual biodegradation

\begin{tabular}{llll}
\hline Compound & $\mathrm{N}^{\circ}$ rings & $\mathrm{mg} / \mathrm{kg}$ & Biodegradation rate (\%) \\
\hline Acenaphthne & 3 & 0.0971 & 94.12 \\
Acenaphtylene & 3 & 0.2337 & 79.62 \\
Anthracene & 3 & 0.3357 & 88.63 \\
Benzo(a)anthracene & 4 & 2.7873 & 91.12 \\
Benzo (a)pyrene & 5 & 2.1496 & 93.54 \\
Benzo(b)fluoranthene & 5 & 5.8541 & 92.93 \\
Benzo(g,h,i)pyrilene & 6 & 2.9744 & 97.54 \\
Benzo(k)fluoranthene & 5 & 3.6323 & 99.03 \\
Crysene & 4 & 3.8234 & 98.68 \\
Dibenzo(a,h)anthracene & 5 & 3.2359 & 95.86 \\
Phenanthrene & 3 & 0.4929 & 61.82 \\
Fluoranthene & 4 & 3.6776 & 91.50 \\
Fluorene & 3 & 0.1621 & 93.15 \\
Indeno(1,2,3,c,d)pyrene & 6 & 0.8687 & 83.52 \\
Nafthalene & 2 & 0.6800 & 99.59 \\
Pyrene & 4 & 3.6957 & 98.75 \\
Sum total & - & 34.0205 & - \\
\hline & & & \\
\hline & & &
\end{tabular}

This occurs because few microorganisms can use these compounds directly as a source of carbon. Benzo(a)pyrene, for instance, presented $93.5 \%$ of degradation; its biotransformation by bacteria is described as possible whenever co-metabolism occurs: bacteria can develop in pyrene, and can degrade benzo(a) pyrene by co-metabolism (Boonchan et al. 2000; Kanaly and Bartha 1999). The presence of the consortium, instead of a pure culture, is an advantage, since when inoculating co-cultures, the actions between their metabolic routes are complementary. These results agree with work on soil contaminated by oily sewage (Li et al. 2008), in which high rates of degradation were found for PAHs, including PAHs with five aromatic rings when using a consortium of bacteria and fungi.

The aromatic compound with the lowest percentage reduction of PAHs in soil, $62 \%$, was phenanthrene, a known molecule with a potential for risks. According to Kiyohara et al. (1994), naphthalene and phenanthrene are degraded by the same metabolic route, and there may have been competition that limited the rates of degradation for phenanthrene. Possibly, the initially existing concentrations were toxic to some native organisms. However, after a longer time of adaptation, the populations that could degrade them were established with evolutionary success to the point that the treatments in general presented a satisfactory performance in degrading the 16 PAHs.

As observed by Trindade et al. (2005) because the mineralization phenomenon is slower than the incomplete transformation route of organic compounds, the efficiency of biodegradation identified by $\mathrm{CO}_{2}$, production will be lower than the chemical concentrations detected analytically. Therefore, when analyzing the results of PAH degradation, the different aspects of transformation must be considered, since there may also be the formation of polar intermediate compounds (Trindade et al. 2005; Lundstedt 2003). Besides that, on the time scale of the experiment, the correspondence between $\mathrm{CO}_{2}$ production and the magnitude of PAHs biodegradation may not be sufficiently well quantified.

This study confirmed that 9CS, with inoculum 2 , showed considerable action on the class of contaminants researched in this field regarding their initial concentration, before the soil was submitted to the microcosm-scale degradation experiment, even with a $\mathrm{CO}_{2}$ production that is not as significant. These results further clarify the responses obtained, since a statistical analysis of data on $\mathrm{CO}_{2}$ production showed a significant 
difference between all treatments in relation to the control soil. However, when inoculum 1 (bioaugmented) and inoculum 2 (bioaugmented, biostimulated, and enriched) are compared, it is found that inoculum 2 presented a greater evolution of $\mathrm{CO}_{2}$ and better performance in the degradation of the contaminants of interest.

\section{Conclusions}

The relevance of using microorganisms native to the contaminated area can be underscored, since the preparation of adapted inoculums showed a better performance when associated with enrichment and biostimulation. It is undeniable that a potential for PAH degradation in the soil itself is found, without any experimental intervention, indicating that the soil of the contaminated area may be undergoing a process of natural attenuation, since the microbial communities in the contaminated area proved active in degrading the contaminants investigated. However, it became clear that with the input of nutrients and bioaugmentation, the capacity of the autochthonous microbiota to biodegrade is optimized, establishing it as an efficient and sustainable process.

It should also be emphasized that the use of consortia improves the bioremediation processes, since the conventional isolation method for later use can employ only a fraction of the various degrading microorganisms present in the environment, and in our experiments, given the high percentage of degradation, possibly occurred complementation between the metabolic pathways. Hence, when we use the integral microbiota in the form of bioaugmented and/or biostimulated/ enriched consortia, it is possible to promote an effective action of microorganisms for the biodegradation of compounds of interest-PAHs, indicating their potential use for bioremediation.

Acknowledgments Our appreciation goes to CAPES for the PhD fellowship, to the Post-Graduate Program in Ecology at UFRGS; to Márcio Olivio Rozin, to Nair Conde Almeida, and Richard Tomasella from UNESP in Rio Claro/SP for helping to set up and implement the respirometry assays and clear technical doubts; to Dr. Carlos E Levy of UNICAMP/SP for the initial identification of the bacteria; to Dr. Derlene Attili de Angelis, also of UNICAMP/SP; and to Prof. Jandyra Fachel, Gilberto P. Mesquita, and Sídia Maria Callegari Jacques for performing the statistical analyses.

\section{References}

Aitken, M. D., Stringfellow, W. T., Nagel, R. D., Kazunga, C., \& Chen, S. H. (1998). Characteristics of phenanthrenedegrading bacteria isolated from soils contaminated with polycyclic aromatic hydrocarbons. Can J Microbiol, 44, 743-752.

Bartha, R., \& Pramer, D. (1965). Features of a flask and method for measuring the persistence and biological effects of pesticides. Soil Sci, 100, 68-70.

Boonchan, S., Britz, M. L., \& Stanley, G. A. (2000). Degradation and mineralization of high-molecular-weight polycyclic aromatic hydrocarbons by defined fungal-bacterial cocultures. Appl Environ Microbiol, 66(3), 1007-1019.

Cerniglia, C. E. (1992). Biodegradation of polycyclic aromatic hydrocarbons. Biodegradation, 3, 351-368.

CETESB. (1990). COMPANHIA DE TECNOLOGIA DE SANEAMENTO AMBIENTAL Norma Técnica L6.350 Solos - Determinação da Biodegradação de Resíduos Método Respirométrico de Bartha (p. 9). São Paulo.

EMBRAPA. (1997). Empresa Brasileira de Pesquisa Agropecuária (Manual de métodos de análise do solo 2nd ed.). Rio de Janeiro: EMBRAPA CNPS. 212p.

FEPAM/CNPq. (2010). Estratégias ecotoxicológicas para caracterizar áreas contaminadas como medida de risco à saúde populacional. Porto Alegre: FEPAM. Project 555187/ 2006-3.

Gaylarde, C. C., Bellinaso, M. D. L., \& Manfio, G. P. (2005). Biotecnologia Ciência \& Desenvolvimento. 34. janeiro/junho.

Gillespie, I. M. M., \& Philp, J. C. (2013). Biotechnology policy series. Bioremediation and environmental remediation, technology for the bioeconomy. Trends Biotechnol, 31(6), 329332.

Giraud, F., Guiraud, P., Kadri, M., Blake, G., \& Steiman, R. (2001). Biodegradation of anthracene and fluoranthene by fungi isolated from an experimental constructed wetland for wastewater treatment. Water Res, 35(17), 4126-4136.

Guerin, T. F. (1999). Bioremediation of phenols and polycyclic aromatic hydrocarbons in creosote contaminated soil using ex-situ land treatment. J Hazard Mater, 65(3), 305-315.

Haritash, A. K., \& Kaushik, C. P. (2009). Biodegradation aspects of polycyclic aromatic hydrocarbons (PAHs): a review. $J$ Hazard Mater, 169, 1-15.

Jacques, R. J. S., et al. (2005). Anthracene biodegradation by Pseudomonas sp isolated from a petrochemical sludge landfarming. Int Biodeterior Biodegrad, 56(3), 150-156.

Jacques, R. J. S., Bento, F. M., Antoniolli, Z. I., \& Camargo, F. A. O. (2007). Biorremediação de solos contaminados com hidrocarbonetos aromáticos policíclicos. Ciência Rural, 37(4), 1192-1201.

Johnsen, A. R., \& Karlson, U. (2007). Diffuse PAH contamination of surface soils: environmental occurrence, bioavailability, and microbial degradation. Appl Microbiol Biotechnol, 76, 533-543.

Juhasz, A. L., Britz, M. L., \& Stanley, G. A. (1997). Degradation of fluoranthene, pyrene, benz[a] anthracene and dibenz $[\mathrm{a}, \mathrm{h}]$ anthracene by Burkholderia cepacia. J Appl Microbiol, 83, 189-198. 
Kanaly, R. A., \& Bartha, R. (1999). Cometabolic mineralization of benzo[a]pyrene caused by hydrocarbon additions to soil. Environ Chem, 18(10), 2186-2190.

Kim, Y. M., Ahn, C. K., Woo, S. H., Jung, G. Y., \& Park, J. M. (2009). Synergic degradation of phenanthrene by consortia of newly isolated bacterial strains. J Biotechnol, 144, 293-298.

Kiyohara, H., Torigoe, S., Kaida, N., Asaki, T., Iida, T., Hayashi, H., \& Takizawa, N. (1994). Cloning and characterization of a chromosomal gene cluster, $\mathrm{PAH}$, that encodes the upper pathway for phenanthrene and naphthalene utilization by pseudomonas putida OUS82. J Bacteriol, 176(8), 24392443.

Kottler, B. D., \& Alexander, M. (2001). Relationship of properties of polycyclic aromatic hydrocarbons to sequestration in soil. Environ Pollut, 113, 293-298.

Li, X., Li, P., Lin, X., Zhang, C., Li, O., \& Gong, Z. (2008). Biodegradation of aged polycyclic aromatic hydrocarbons (PAHs) by microbial consortia in soil and slurry phases. $J$ Hazard Mater, 150(1), 21-26.

Li, X., Lin, X., Li, P., Liu, W., Wang, L., Ma, F., \& Chukwuka, K. S. (2009). Biodegradation of the low concentration of polycyclic aromatic hydrocarbons in soil by microbial consortium during incubation. J Hazard Mater, 172, 601-605.

Lladó, S., Covino, S., Solanas, A. M., Vinas, M., Petruccioli, M., \& D'Annibaled, A. (2013a). Comparative assessment of bioremediation approaches to highly recalcitrant PAH degradation in a real industrial polluted soil. J Hazard Mater. doi:10.1016/j.jhazmat.2013.01.020.

Lladó, S., Gràcia, E., Solanas, A. M., \& Viñas, M. (2013b). Fungal and bacterial microbial community assessment during bioremediation assays in an aged creosote-polluted soil. Soil Biol Biochem, 67, 114-123.

Lundstedt, S. (2003). Analysis of PAHs and their transformation products in contaminated soil and remedial processes. Umea: Department of Chemistry Environmental Chemistry Umeå University SE-901 200387.

Mariano, A. P., Angelis, D. F., Pirôllo, M. P. S., Contiero, J., \& Bonotto. (2009). Investigation about the efficiency of the bioaugmentation technique when applied to diesel oil contaminated soils. Braz Arch Biol Technol, 52(5), 1297-1312.

Megharaj, M., Ramakrishnane, B., Venkateswarlu, K., Sethunathan, N., \& Naidu, R. (2011). Bioremediation approaches for organic pollutants: a critical perspective. Environ Int, 37, 1362-1375.

Mizwar, A., \& Triha, Y. (2015). PAH contamination in soils adjacent to a coal-transporting facility in Tapin district, south Kalimantan, Indonesia. Arch Environ Contam Toxicol, 69, $62-68$.

Moscoso, F., Teijiz, I., Deive, F. J., \& Sanroman, M. A. (2012). Efficient PAHs biodegradation by bacterial consortium at flask and bioreactor scale. Bioresour Technol, 119, 270-276.

NBR 14283. (1999). Resíduos em solos: determinação da biodegradação pelo método respirométrico. RJ.

Pohren, R., Rocha, J., Leal, K., \& Vargas, V. (2012). Soil mutagenicity as a strategy to evaluate environmental and health risks in a contaminated area. Environ Int, 44, 40-52.
Posada-Baquero, R., \& Ortega-Calvo, J. J. (2011). Recalcitrance of polycyclic aromatic hydrocarbons in soil contributes to background pollution. Environ Pollut, 159, 3692-3699.

Rahman, K. S. M., Thahira, J., Kourkoutas, Y., Petsas, I., Marchant, R., \& Banat, I. M. (2003). Enhanced bioremediation of n-alkane in petroleum sludge using bacterial consortium amended with rhamnolipid and micronutrients. Bioresour Technol, 90(2), 159-168.

Sayara, T., Borràs, E., Caminal, G., Sarràa, M., \& Sáncheza, A. (2011). Bioremediation of PAHs-contaminated soil through composting: influence of bioaugmentation and biostimulation on contaminant biodegradation. Int Biodeter Biodegr, $65,859-865$.

Semple, K. T., Kieron, J. D., Wick, L. Y., \& Harms, H. (2007). Microbial interactions with organic contaminants in soil: definitions, processes and measurement. Environ Pollut, 150, 166-176.

Serrano, I. S., dos Santos, E. C., Menezes, C. R., de Faria, A. F., Franciscon, E., Grossman, M., \& Durrant, L. R. (2009). Bioremediation of a polyaromatic hydrocarbon contaminated soil by native soil microbiota and bioaugmentation with isolated microbial consortia. Bioresour Technol, 100, 4669-4675.

Standard methods for the examination of water wastewater. (1995). American Public Health Association/American water Works Association/Water Environment Federation, Washington (19th ed.)

Sun, R., Jin, J., Sun, G., Liu, Y., \& Liu, Z. (2010). Screening and degrading characteristics and community structure of a high molecular weight polycyclic aromatic hydrocarbondegrading bacterial consortium. J Environ Sci, 22(10), 1576-1585.

Trindade, P. V., Sobral, L. G., Rizzo, A. C., Leite, S. G., \& Soriano, A. U. (2005). Bioremediation of a weathered and a recently oil-contaminated soils from Brazil: a comparison study. Chemosphere, 58(4), 515-522.

Trzesicka-Mlynarz, D., \& Ward, O. P. (1995). Degradation of polycyclic aromatic hydrocarbons (PAHs) by a mixed culture and its component pure cultures, obtained from $\mathrm{PAH}-$ contaminated soil. Can J Microbiol, 41, 470-476.

USEPA-U.S. Environmental Protection Agency. (1996a). Method 8270C: semivolatile organic compounds by gas chromatography/mass spectrometry (GC/MS).

USEPA-U.S. Environmental Protection Agency. (1996b). Soil screening guidance: user's guide. Publication 9355.4-23 (p. 39). Washington, DC: Office of Solid Waste and Emergency Response.

USEPA-U.S. Environmental Protection Agency. (2007). Method 3550C, Ultrasonic extraction. . http://www.epa.gov/sw846 /pdfs/3500.pdf

White, P. A., Lemieux, C. L., Lynes, K. D., Lambert, I. B., Öberg, L., Haglund, P., \& Tysklind, M. (2007). Sources, fate, and toxic hazards of oxygenated polycyclic aromatic hydrocarbons (PAHs) at PAH-contaminated sites. AMBIO, 36(6), 475-485.

Zafra, G., \& Cortés-Espinosa, D. V. (2015). Biodegradation of polycyclic aromatic hydrocarbons by Trichoderma species: a mini review. Environ Sci Pollut Res. doi:10.1007/s11356015-5602-4. 